\title{
Pulse pressure and end-tidal carbon dioxide for monitoring low native cardiac output during veno-arterial ECLS: a prospective observational study
}

Marc Mourad ${ }^{1 *}$ D, Jacob Eliet ${ }^{1}$, Norddine Zeroual ${ }^{1}$, Marine Saour ${ }^{1}$, Pierre Sentenac ${ }^{1}$, Federico Manna², Nicolas Molinari ${ }^{2}$, Thomas Gandet ${ }^{3}$, Pascal H. Colson ${ }^{1,4 \dagger}$ and Philippe Gaudard ${ }^{1,5+}$

\begin{abstract}
Background: Veno-arterial extracorporeal life support (VA-ECLS) results in cardiopulmonary shunting with reduced native cardiac output (NCO). Low NCO occurrence is common and associated with risk of thromboembolic and pulmonary complications. Practical tools for monitoring NCO during VA-ECLS would therefore be valuable. Pulse pressure (PP) and end-tidal carbon dioxide $\left(\mathrm{EtCO}_{2}\right)$ are known to be related to cardiac output. We have designed a study to test whether PP and $\mathrm{EtCO}_{2}$ were efficient for the monitoring of NCO during VA-ECLS.

Methods: In this prospective single-center observational study, patients who underwent a VA-ECLS for cardiogenic shock from January 2016 to October 2017 were included, provided low NCO was suspected by a PP $<20$ mmHg. $\mathrm{NCO}$ was measured with pulmonary artery catheter or echocardiography and compared to PP and $\mathrm{EtCO}_{2}$. The ability of PP and $\mathrm{EtCO}_{2}$ to predict $\mathrm{NCO}<1 \mathrm{~L} /$ min was evaluated with receiver operating characteristics (ROC) curves.

Results: Among the 106 patients treated with VA-ECLS for cardiogenic shock during the study period, 26 were studied, allowing the collection of 196 study points. PP and $\mathrm{EtCO}_{2}$ relationships with $\mathrm{NCO}$ were nonlinear and showed strong correlations for $\mathrm{NCO}<2 \mathrm{~L} / \mathrm{min}\left(r=0.69\right.$ and $r=0.78$ respectively). A PP $<15 \mathrm{mmHg}$ and $\mathrm{EtCO}_{2}<14$ $\mathrm{mmHg}$ had good predictive values for detecting $\mathrm{NCO}<1 \mathrm{~L} / \mathrm{min}$ (area under ROC curve 0.93 [95\% Cl 0.89-0.96] and 0.97 [95\% Cl 0.94-0.99] respectively, $p=0.058$ ).

Conclusions: PP and $\mathrm{EtCO}_{2}$ may offer an accurate real-time monitoring of low NCO events during VA-ECLS support. Further studies are needed to show if their utilization may help to implement therapeutic strategies in order to prevent thromboembolic and respiratory complications associated with VA-ECLS, and to improve patients' prognosis.
\end{abstract}

Trial registration: NCT03323268, July 12, 2016

Keywords: Cardiogenic shock, VA-ECLS support, $\mathrm{EtCO}_{2}$, Pulse pressure

\footnotetext{
*Correspondence: m-mourad@chu-montpellier.fr

${ }^{\dagger}$ Pascal H. Colson and Philippe Gaudard contributed equally to this work. 'Department of Anesthesiology and Critical Care Medicine, Arnaud de Villeneuve Hospital, CHU Montpellier, Univ Montpellier, Montpellier, France Full list of author information is available at the end of the article
}

(c) The Author(s). 2020 Open Access This article is licensed under a Creative Commons Attribution 4.0 International License, which permits use, sharing, adaptation, distribution and reproduction in any medium or format, as long as you give appropriate credit to the original author(s) and the source, provide a link to the Creative Commons licence, and indicate if changes were made. The images or other third party material in this article are included in the article's Creative Commons licence, unless indicated otherwise in a credit line to the material. If material is not included in the article's Creative Commons licence and your intended use is not permitted by statutory regulation or exceeds the permitted use, you will need to obtain permission directly from the copyright holder. To view a copy of this licence, visit http://creativecommons.org/licenses/by/4.0/ The Creative Commons Public Domain Dedication waiver (http://creativecommons.org/publicdomain/zero/1.0/) applies to the data made available in this article, unless otherwise stated in a credit line to the data. 


\section{Introduction}

Peripheral veno-arterial extracorporeal life support (VAECLS) for severe acute cardiac failure is increasingly used in patients with refractory cardiogenic shock (CS) or persistent cardiac arrest, either as a bridge to myocardial recovery, or to cardiac transplantation, or to longterm mechanical circulatory support [1-3]. However, although it provides good circulatory assistance, VAECLS has anti-physiological hemodynamic consequences, mainly, bypass of pulmonary circulation and backflow into the aorta. Indeed, VA-ECLS diverts venous return from the right atrium, reducing right ventricle pre-load, and returns blood into the aorta, increasing left ventricle (LV) afterload. It results in a proportional reduction of the pulmonary blood flow generated by the right and left ventricles (so-called, native cardiac output, NCO). Many adverse hemodynamic effects of VA-ECLS are related to these antiphysiological effects such as LV distension, pulmonary edema, and blood stasis in the pulmonary artery, cardiac chambers, or aortic root with high risk of thrombosis [4-6]. Moreover, low NCO during ECLS can induce significant pulmonary lesions and may be prevented by maintaining $25 \%$ of the systemic cardiac output through the pulmonary artery [7].

To overcome these drawbacks, current practices consist in tracking pulmonary edema, LV distension with spontaneous echo contrast (SEC), and aortic valve opening, mainly with repeated echocardiography exams [8]. Patients may then benefit from LV venting techniques to avoid the most serious complications [9-13]. The primary aim of venting techniques is LV discharge and prevention of pulmonary edema. Various techniques are proposed, with small differences in efficacy [14]. They differ in their ability to maintain or regulate NCO, but comparative data are not currently available. Therefore, monitoring NCO during VA-ECLS seems desirable to prevent the related complications. NCO is usually assessed by pulmonary artery catheter (PAC) with thermodilution measurement of right ventricle output, assuming the coupling of right and left ventricles results in the same output for both sides, and provided there is no left/right shunt. However, the technique is invasive and less reliable when cardiac output is low $[15,16]$. Echocardiography is the alternative technique, either by directly measuring pulmonary artery flow (but this needs direct access to the pulmonary valve which is better viewed by trans-esophageal echocardiography) or by evaluating LV outflow by Doppler through the aortic valve (which can be obtained by transthoracic echocardiography). Nevertheless, whatever the echography technique, it cannot be considered as a monitoring technique. Often, the pulse pressure (PP) measured from the arterial line is used as a surrogate to assess $\mathrm{NCO}$, but no study has yet addressed the issue of how much PP is sufficient. Similarly, end-tidal carbon dioxide $\left(\mathrm{EtCO}_{2}\right)$ follows changes in cardiac output, provided $\mathrm{CO}_{2}$ production and removal are stable $[17,18]$. In this respect, we recently observed a good correlation between $\mathrm{EtCO}_{2}$ and NCO in patients on VA-ECLS submitted to gradual increases of left-sided Impella assistance. The $\mathrm{EtCO}_{2}$ increase correlated quite well with the increased NCO assessed by echocardiography Doppler [19].

Based on these observations, we designed this study in order to assess the performance of $\mathrm{PP}$ and $\mathrm{EtCO}_{2}$ in evaluating $\mathrm{NCO}$, and their accuracy to detect $\mathrm{NCO}$ below $1 \mathrm{~L} /$ min during VA-ECLS.

\section{Materials and methods Study design}

This is a prospective, observational, cohort study, approved by our institutional review board (CPP Sud Mediterranée 1; ID RCB: 2015-A02006-43). Informed consent was obtained from all patients or their surrogates. The trial was retrospectively registered on Clinicaltrials.gov on July 12, 2016 (NCT03323268).

\section{Settings}

The study was conducted in our tertiary hospital intensive care unit (ICU) from January 2016 to October 2017. Observations were recorded within the first $48 \mathrm{~h}$ after VA-ECLS implantation and up to 5 days after.

\section{Participants}

All consecutive VA-ECLS patients admitted to our ICU during the study period were prescreened. Only the patients who experienced a PP $<20 \mathrm{mmHg}$ were eligible, assuming the fact that $\mathrm{PP}<20 \mathrm{mmHg}$ could be considered, a priori, as a marker of low NCO. Patients were included if PAC was available. All included patients were followed afterwards over a maximum of 5 days, during which monitoring allowed several study points (see below) at various levels of NCO. Exclusion criteria included non-invasive ventilation at the time of screening, age less than 18 years, pulmonary disorders (obstructive pulmonary disease; acute respiratory distress syndrome, CS due to massive pulmonary embolism); intra-cardiac shunt (atrial or ventricular communication), and significant tricuspid or pulmonary valve disease. Left ventricular assist device (VAD) was not considered as exclusion criteria whenever VAD outflow was $<1.5 \mathrm{~L} / \mathrm{min}$.

VA-ECLS consisted of polyvinyl chloride tubing with a membrane oxygenator (PH.I.S.I.O and EOS; Sorin Group, Clamart, France), a centrifugal pump (Stockert; Sorin Group), and percutaneous or surgically inserted arterial and venous femoral cannulas (Fem-Flex and Fem-Track, Edwards Lifesciences, Guyancourt, France) with an additional 7F cannula inserted distally into the 
femoral artery to prevent lower limb ischemia. An oxygen-air blender (Sechrist Industries, Anaheim, CA) ventilated the membrane oxygenator. Unfractionated heparin was administrated to maintain an anti-factor-Xa activity of between 0.2 and $0.3 \mathrm{IU} / \mathrm{mL}$.

In the initial phase of the circulatory assistance, VA-ECLS flow was set to provide adequate tissue perfusion (mixed venous oxygen saturation measured from the distal lumen of the PAC, $\mathrm{SVO}_{2} \geq 65 \%$ ) and to obtain correction of metabolic acidosis (serum lactate clearance). Thereafter, the VA-ECLS flow was set at the lowest rate necessary to ensure adequate tissue perfusion, while the highest NCO was wanted. Lung ventilation was managed with low levels of respiratory rate $(10-14$ breaths $/ \mathrm{min})$ and tidal volume $(4-6 \mathrm{~mL} /$ $\mathrm{kg}$ ), and with a modest level of positive endexpiratory pressure $\left(8-10 \mathrm{cmH}_{2} \mathrm{O}\right)$ to ensure protective ventilation [20]. Respiratory minute ventilation and ECLS sweep gas flow were adjusted to maintain baseline $\mathrm{PaCO}_{2}$ in a normal range, of around 40 $\mathrm{mmHg}$.

In the case of severe LV distension, defined by pulmonary edema and/or threatening SEC on echocardiography, LV decompression (LV venting) was realized using transient left VAD (CP or 5.0 Impella devices, Abiomed Europe $\mathrm{GmbH}$, Aachen, Germany).

\section{Outcome variables: native cardiac output, pulse pressure, and $\mathrm{EtCO}_{2}$}

NCO was assessed by continuous (heated filament) thermodilution PAC (Swan-Ganz CCOmbo ${ }^{\circ} \mathrm{CCO} / \mathrm{SvO}_{2}$, Edwards Lifesciences) inserted through the superior vena cava with placement confirmed by chest radiography. When NCO estimated by PAC was not possible (i.e., when the PAC monitor displayed "cardiac output < $\left.1 \mathrm{~L} / \mathrm{min}^{\prime}\right)$, an evaluation of aortic and/or pulmonary outflow using Doppler echocardiography (transthoracic or trans-esophageal) was performed. An NCO threshold of $1 \mathrm{~L} / \mathrm{min}$ was used to define threatening NCO (Th-NCO), considering $\mathrm{NCO}<1 \mathrm{~L} / \mathrm{min}$ at the higher risk of complications.

Continuous blood pressure was monitored via a radial arterial catheter. PP was defined as systolic arterial pressure-diastolic arterial pressure and studied only in the absence of concomitant left VAD.

$\mathrm{EtCO}_{2}$ was measured noninvasively from exhaled breath on a ventilator circuit and monitored using a ventilator $\mathrm{CO}_{2}$ analyzer (Maquet servo $\mathrm{U}$, Drager Evita Infinity V500). Moreover, the arterial-to-end-tidal carbon dioxide $\left(\mathrm{PaCO}_{2}-\mathrm{EtCO}_{2}\right)$ gradient was calculated as $\mathrm{PaCO}_{2}-\mathrm{EtCO}_{2}, \mathrm{PaCO}_{2}$ being measured from arterial blood gas analysis (GEM4000premier ${ }^{\odot}$, Instrumentation Laboratory).

\section{Data collection}

The following parameters were recorded: demographic characteristics, etiology of cardiac failure, context and patient severity at VA-ECLS implantation, hemodynamic variables and circulatory support at inclusion, and clinical course during VA-ECLS and follow-up.

Concomitant measurements of $\mathrm{NCO}, \mathrm{PP}$, and $\mathrm{EtCO}_{2}$ were realized in stable condition (no change in VAECLS and ventilator settings, patients' treatment including hemodynamic supports and level of sedation). These study points were aimed first at ensuring that the VAECLS setting was optimal and also for catching Th-NCO events. The measurements were thus repeated, up to 4 a day, until NCO became $>2 \mathrm{~L} / \mathrm{min}$. Afterward, the measurements were made at the operator's discretion, at least once a day, during the time of PAC monitoring.

The following data were also collected: hemodynamic support (catecholamine infusion, inhaled nitric oxide, cardiac pacing), left VAD outflow (if present), heart rate, systemic blood pressure, pulmonary artery pressures (PAP), pulmonary arterial wedge pressure (PAWP), $\mathrm{SvO}_{2}$, ventilator and VA-ECLS settings (respiratory mode, tidal volume, respiratory rate, positive endexpiratory pressure, plateau pressure, VA-ECLS, and sweep gas outputs), and blood gases sampled from the radial artery.

\section{Study size}

We anticipated collecting data from eligible patients until obtaining at least 50 observations of Th-NCO.

\section{Statistical analysis}

Categorical variables (expressed as absolute value and percentage) were compared using the chi-squared test. Continuous variables (expressed as median [25th-75th percentile]) were compared with Student's $t$ test or the Mann-Whitney $U$ test, as appropriate according to the normality distribution assessed graphically.

The relationships of $\mathrm{PP}$ and $\mathrm{EtCO}_{2}$ with $\mathrm{NCO}$ were assessed graphically. The relationships of pulse pressure with stroke volume and $\mathrm{PaCO}_{2}-\mathrm{EtCO}_{2}$ gradient with $\mathrm{NCO}$ were studied to consider heart rate and $\mathrm{PaCO}_{2}$ confounders respectively. As these analyses showed nonlinear links for some variables, they were fitted in a regression model using a cubic spline [21]. The link between variables and the effect of uneven V/Q ratios (absolute difference to 1) at lungs and ECLS membrane on the relationship between $\mathrm{EtCO}_{2}$ and $\mathrm{NCO}$ were studied through an error prediction model (variations of model performance according to $X$ or confounders). The $\mathrm{NCO}<2 \mathrm{~L} / \mathrm{min}$ level was identified as a cut-off value by calculating and comparing correlations from either side of several NCO levels using the weighted Spearman test and Zou's confidence interval respectively. 
The ability of PP and $\mathrm{EtCO}_{2}$ to predict Th-NCO was evaluated with receiver operating characteristics (ROC) curves and quantified by calculating the area under the curve (AUC) and 95\% CI. A Delong test was used to compare matched ROC curves. The optimal threshold to predict Th-NCO was then determined as the one that minimized the explicit cost ratio, which is equivalent to maximizing Youden's index. Statistical significance was defined as $p<0.05$. The statistical analyses were performed using $\mathrm{R}$ environment (version 3.2.2, $\mathrm{R}$ Foundation, Vienna, Austria).

\section{Results}

\section{Participants}

Among the 106 patients treated with VA-ECLS during the study period, 72 presented an occurrence of $\mathrm{PP}<20$ $\mathrm{mmHg}$ and 26 had a PAC (Fig. 1, flowchart). Baseline patient characteristics, VA-ECLS management, and follow-up are displayed in Table 1. Five patients received VA-ECLS while already on transient or durable left VAD support and 4 patients required transient left VAD for severe LV distension during VA-ECLS.

\section{NCO measurements}

Eight [5-9] measurements were realized per patient, totaling 196 study points. Fifty-one (26\%) Th-NCO

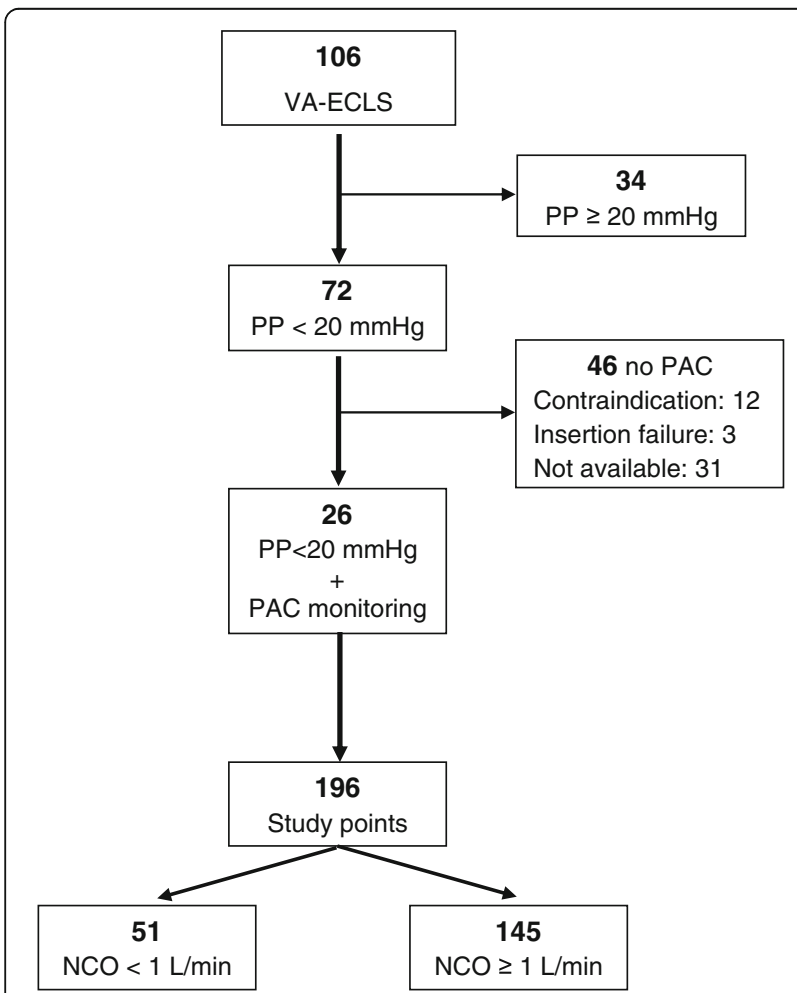

Fig. 1 Flowchart. VA-ECLS, veno-arterial extracorporeal life support; $\mathrm{PP}$, pulse pressure; PAC, pulmonary artery catheter; $\mathrm{NCO}$, native cardiac output
Table 1 Patients' characteristics, clinical course, and outcomes in intensive care unit

\begin{tabular}{ll}
\hline Men & $16(62)$ \\
Age, years & $63[58-70]$ \\
Body mass index & $25[23-29]$ \\
Cardiogenic shock etiology & \\
Post cardiotomy & $11(42)$ \\
Acute myocardial infarction & $8(31)$ \\
Dilated cardiomyopathy & $5(19)$ \\
Others & $2(8)$
\end{tabular}

Clinical and biological variables at VA-ECLS implantation

Resuscitation before VA-ECLS

9 (35)

VA-ECLS under CPR

$4(15)$

SOFA score

$12[12-13]$

Durable left VAD

$1(4)$

Transient left VAD

$4(15)$

IABP

$0(0)$

Serum lactate, $\mathrm{mmol} / \mathrm{L}$

$7.1[4.5-9.7]$

Prothrombin time, \%

$56[44-64]$

Hemodynamic variables at inclusion (=1st study point)

$\begin{array}{ll}\text { Heart rate, beats/min } & 90[77-100] \\ \text { Cardiac pacing } & 6(23) \\ \text { Norepinephrine, mg/h } & 3[1.3-5.1] \\ \text { Inotropic support } & 14(54) \\ \text { Inhaled nitric oxide } & 7(27) \\ \text { VA-ECLS flow, L/min } & 3.4[2.9-4.1] \\ \text { Left VAD flow if present, L/min } & 0.9[0.4-1.5] \\ \text { Clinical course in ICU } & \\ \text { Days under VA-ECLS } & 8[6-10] \\ \text { Add of transient left VAD during VA-ECLS } & 4(15) \\ \text { Add of IABP during VA-ECLS } & 0(0) \\ \text { Renal replacement therapy } & 10(38) \\ \text { Successful VA-ECLS weaning } & 18(69) \\ \text { Outcomes } & \\ \text { Length of ICU stay, days } & 21[13-31] \\ \text { ICU survival } & 13(50) \\ \text { 6-month survival } & 11(42)\end{array}$

ata are expressed as median [IOR interquartile range], or $N(\%)$ $V A-E C L S$ veno-arterial extracorporeal life support, CPR cardiopulmonary resuscitation, SOFA Sepsis-Related Organ Failure Assessment, VAD ventricular assist device, ICU intensive care unit, IABP intra-aortic balloon pump

episodes were collected, mainly during the first hours (1 h [0-15]) of VA-ECLS. NCO $\geq 1 \mathrm{~L} / \mathrm{min}$ study points $(n=145,74 \%)$ were recorded later (median 30th hour [8-65]). Forty-seven (24\%) of the study points were recorded while left VAD support 
was running ( $=$ missing data for pulse pressure), with a similar proportion between Th-NCO events and other study points (Table 2).

Eighteen (69\%) patients presented at least one episode of Th-NCO and 13 (50\%) had Th-NCO at the first measurement. Respiratory and hemodynamic variables according to $\mathrm{NCO}<$ or $\geq 1 \mathrm{~L} / \mathrm{min}$ are reported in Table 2 .

\section{Pulse pressure and NCO}

As shown in Fig. 2a, PP relationship with $\mathrm{NCO}$ described a nonlinear regression curve. The spline regression model error increased significantly with $\mathrm{NCO} \quad(p<0.001$ with positive coefficient), which means that the model fitted better for lower NCO values. A similar relationship was observed between $\mathrm{PP}$ and stroke volume, with the spline regression model error significantly increased with NCO $(p<0.001)$ (Fig. 2b).

Since the relationship between $\mathrm{PP}$ and $\mathrm{NCO}<2 \mathrm{~L} / \mathrm{min}$ was covering the $\mathrm{NCO}$ values of interest, we also tested a linear fitting, which showed a correlation coefficient of 0.694 [CI 0.570-0.786].

Table 2 Respiratory and hemodynamic data according to native cardiac output (NCO) $<1 \mathrm{~L} / \mathrm{min}$ versus $\geq 1 \mathrm{~L} / \mathrm{min}$

\begin{tabular}{|c|c|c|c|}
\hline & $\mathrm{NCO}<1 \mathrm{~L} / \min (n=51)$ & $\mathrm{NCO} \geq 1 \mathrm{~L} / \mathrm{min}(n=145)$ & $p$ value \\
\hline \multicolumn{4}{|l|}{ VA-ECLS and ventilator data } \\
\hline VA-ECLS flow (Q ECLS), L/min & $3.2[2.9-4]$ & $2.9[2.2-3.8]$ & $<0.01$ \\
\hline VA-ECLS sweep gas flow (V ECLS), L/min & $5[4-6]$ & $4[3-5]$ & $<0.01$ \\
\hline V/Q ECLS & $1.3[1.2-1.7]$ & $1.4[1.1-1.8]$ & 0.96 \\
\hline Tidal volume, $\mathrm{mL}$ & $300[260-350]$ & $320[300-360]$ & $<0.001$ \\
\hline Respiratory rate, breaths/min & $12[11-14]$ & $12[11-14]$ & 0.65 \\
\hline Ventilator minute volume (V lung), L/min & $3.6[3-4]$ & $3.9[3.5-4.7]$ & $<0.01$ \\
\hline Positive end-expiratory pressure, $\mathrm{CmH}_{2} \mathrm{O}$ & $10[8-10]$ & $10[8-10]$ & 0.91 \\
\hline Plateau pressure, $\mathrm{cmH}_{2} \mathrm{O}$ & 18 [17-21] & 18 [16-20] & 0.26 \\
\hline V lung $N$ ECLS & $0.8[0.6-1]$ & $1.1[0.8-1.2]$ & $<0.001$ \\
\hline \multicolumn{4}{|l|}{ Hemodynamic data } \\
\hline Heart rate, beats/min & 88 [73-107] & 87 [72-106] & 0.66 \\
\hline Right atrium pressure, $\mathrm{mmHg}$ & $7[5-8]$ & $11[8-13]$ & 0.01 \\
\hline PA systolic pressure, $\mathrm{mmHg}$ & 15 [12-18] & 26 [23-34] & $<0.001$ \\
\hline PA diastolic pressure, $\mathrm{mmHg}$ & $12[9-15]$ & 19 [16-21] & $<0.001$ \\
\hline Mean PA pressure, $\mathrm{mmHg}$ & $13[10-17]$ & 21 [18-26] & $<0.001$ \\
\hline PA wedge pressure, $\mathrm{mmHg}$ & $10[8-12]$ & $14[11-16]$ & 0.01 \\
\hline $\mathrm{NCO}, \mathrm{L} / \mathrm{min}$ & $0.5[0.15-0.5]$ & $1.8[1.4-2.7]$ & $<0.001$ \\
\hline Systolic BP, mmHg & 79 [73-88] & 95 [84-109] & $<0.001$ \\
\hline Diastolic BP, mmHg & 73 [67-79] & 70 [63-77] & 0.13 \\
\hline Pulse pressure, $\mathrm{mmHg}$ & $9[0-14]$ & 31 [20-42] & $<0.001$ \\
\hline Mean $\mathrm{BP}, \mathrm{mmHg}$ & 74 [69-80] & 78 [72-87] & $<0.01$ \\
\hline $\mathrm{SvO}_{2}(\%)$ & 74 [72-78] & $72[66-77]$ & 0.10 \\
\hline \multicolumn{4}{|l|}{ Respiratory data } \\
\hline $\mathrm{PaCO}_{2}, \mathrm{mmHg}$ & 35 [33-40] & $37[34-41]$ & 0.26 \\
\hline $\mathrm{EtCO}_{2}, \mathrm{mmHg}$ & $9[2-12]$ & 23 [17-28] & $<0.001$ \\
\hline $\mathrm{PaCO}_{2}-\mathrm{EtCO}_{2}, \mathrm{mmHg}$ & 30 [22-33] & 13 [8-19] & $<0.001$ \\
\hline \multicolumn{4}{|l|}{ Adjuvant treatments } \\
\hline Norepinephrine (mg/h) & $3.2[2.9-4]$ & $1.2[0.2-0.4]$ & $<0.01$ \\
\hline Inotropic support & $34(67)$ & $41(28)$ & $<0.001$ \\
\hline Inhaled NO & $12(23)$ & $21(14)$ & 0.07 \\
\hline Transient or durable left VAD & $11(21)$ & $38(26)$ & 0.57 \\
\hline
\end{tabular}

Data are expressed as median [IQR interquartile range], or $N(\%)$

$\mathrm{NCO}$ native cardiac output, VA-ECLS veno-arterial extracorporeal life support, $E t \mathrm{CO}_{2}$ end-tidal carbon dioxide, $\mathrm{PaCO}$-EtCO ${ }_{2}$ arterial-to-end-tidal carbon dioxide gradient, $B P$ blood pressure, $P A$ pulmonary artery, $\mathrm{SvO}_{2}$ mixed venous oxygen saturation, $N O$ nitric oxide, $V A D$ left ventricular assist device 

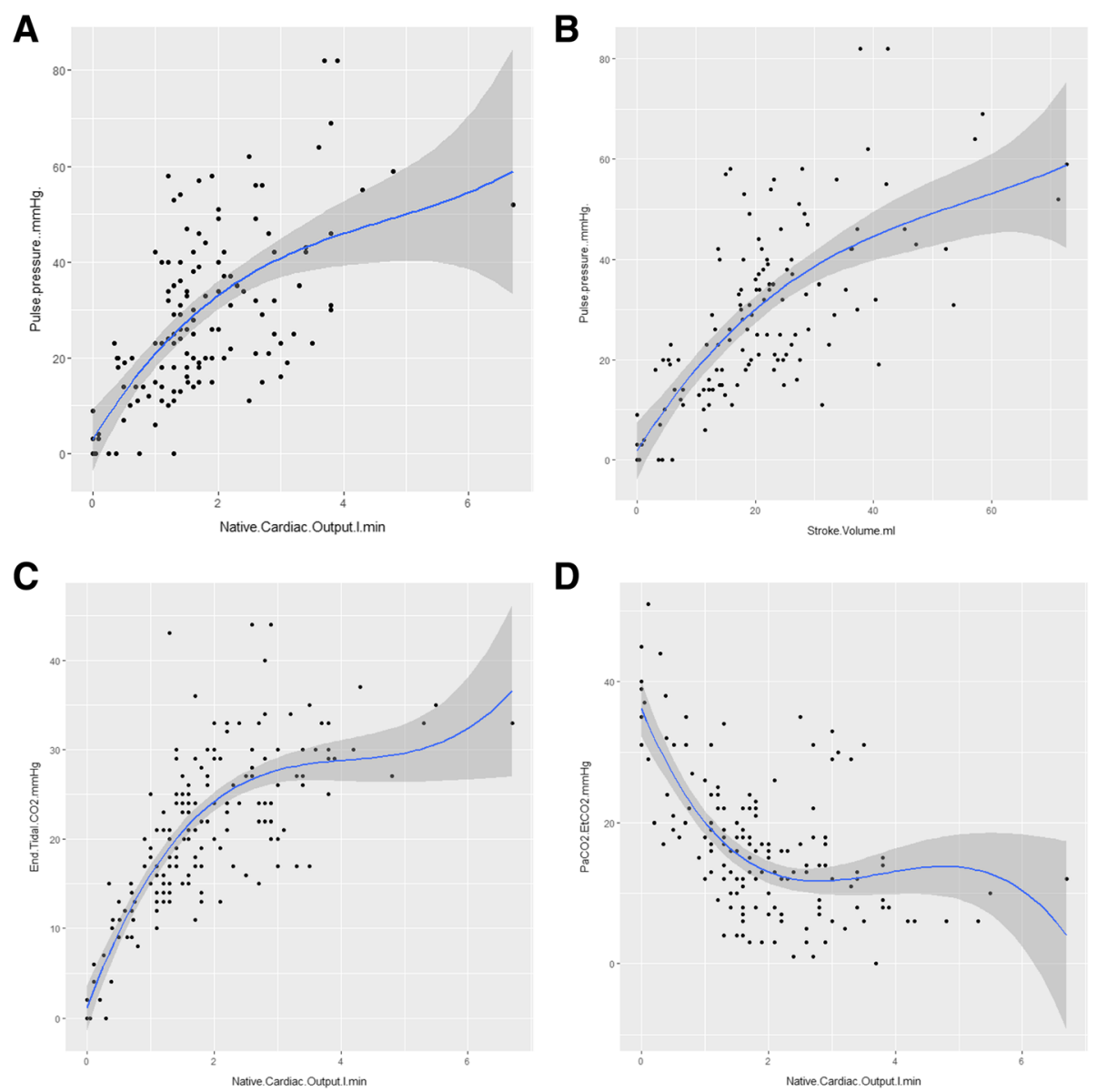

Fig. 2 Pulse pressure and $\mathrm{EtCO}_{2}$ relationships with native cardiac output and their determinants. Native cardiac output was assessed with pulmonary artery catheter or echocardiography at the same time as pulse pressure, end-tidal carbon dioxide $\left(\mathrm{EtCO}_{2}\right)$, arterial carbon dioxide pressure $\left(\mathrm{PaCO}_{2}\right.$ ), and heart rate. Figures consist of spline regression representations (cubic spline, $\mathrm{P}$ Bruce and Bruce 2017) of the relationships between a pulse pressure and native cardiac output, $\mathbf{b}$ pulse pressure and stroke volume, $\mathbf{c} \mathrm{EtCO}_{2}$ and native cardiac output, and $\mathbf{d} \mathrm{PaCO}_{2}-\mathrm{EtCO}_{2}$ gradient and native cardiac output. The variation of model performance according to the $X$ was evaluated through prediction of the error model $(p<0.001, p<0.001, p=0.01$, and $p=0.3$ for figures $\mathbf{a}, \mathbf{b}, \mathbf{c}$, and $\mathbf{d}$ respectively)

\section{End-tidal $\mathrm{CO}_{2}$ and $\mathrm{NCO}$}

As shown in Fig. 2c, EtCO 2 relationship with $\mathrm{NCO}$ also described a nonlinear regression curve. The spline regression model error increased significantly with $\mathrm{NCO}(p=0.01$ with positive coefficient), which means that the model fitted better for lower NCO values. Indeed, linear fitting between $\mathrm{EtCO}_{2}$ and $\mathrm{NCO}<2 \mathrm{~L} / \mathrm{min}$ found a correlation coefficient of 0.779 [CI $0.683-0.848$ ].

Of note, uneven $\mathrm{V} / \mathrm{Q}$ ratios at lungs and membrane did not affect the relation between $\mathrm{EtCO}_{2}$ and $\mathrm{NCO}(p=0.15$ and $p=0.1$ for V/Q ECLS and V/Q lung respectively).

A similar biphasic correlation was observed for the $\mathrm{PaCO}_{2}-\mathrm{EtCO}_{2}$ gradient but in the opposite direction to $\mathrm{EtCO}_{2}$ (Fig. 2d), and with weaker correlation coefficient $(-0.560[-0.685-0.402])$ when considering the linear regression between $\mathrm{PaCO}_{2}-\mathrm{EtCO}_{2}$ gradient and $\mathrm{NCO}<2 \mathrm{~L} / \mathrm{min}$.
Accuracy of pulse pressure and $\mathrm{EtCO}_{2}$ to predict Th-NCO The best cut-off values for predicting Th-NCO were $14.5 \mathrm{mmHg}$ for PP (sensitivity $=0.83$, specificity $=0.90$, positive predictive value $=0.75$, negative predictive value $=0.93$ ) and $13.5 \mathrm{mmHg}$ for $\mathrm{EtCO}_{2}$ (sensitivity = 0.88 , specificity $=0.93$, positive predictive value $=0.82$, negative predictive value $=0.95$ )

ROC curve analysis of PP and $\mathrm{EtCO}_{2}$ cut-off values are shown in Fig. 3. ROC AUC tended to be higher for $\mathrm{EtCO}_{2}$ than for PP $(0.97[0.94-0.99]$ and 0.93 [0.89$0.96]$ respectively, $p=0.058$ ).

\section{Discussion}

This prospective study shows that, during VA-ECLS, PP and $\mathrm{EtCO}_{2}$ are strongly correlated with $\mathrm{NCO}$ when it is lower than $2 \mathrm{~L} / \mathrm{min}$. PP $<15 \mathrm{mmHg}$ and $\mathrm{EtCO}_{2}<14$ $\mathrm{mmHg}$ predicted Th-NCO $(\mathrm{NCO}<1 \mathrm{~L} / \mathrm{min})$ with good accuracy. Monitoring these parameters may help to 


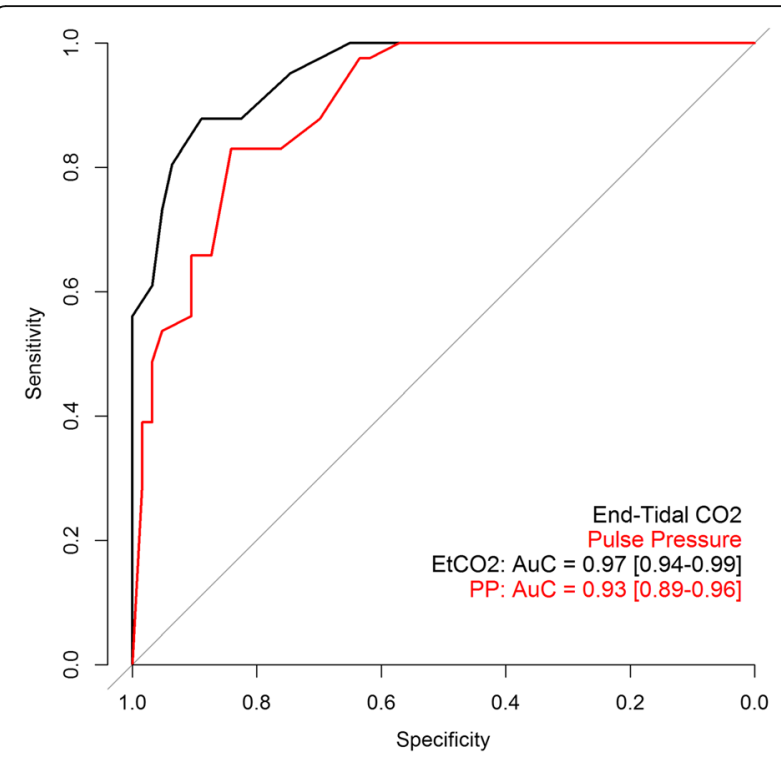

Fig. $3 \mathrm{ROC}$ AUCs of pulse pressure and $\mathrm{EtCO}_{2}$ for predicting native cardiac output $<1 \mathrm{~L} / \mathrm{min}$. ROC curve for pulse pressure (PP) in red and for end-tidal carbon dioxide $\left(\mathrm{EtCO}_{2}\right)$ in black. Receiver operating characteristics (ROC) curves quantified by area under the curve (AUC) and 95\% Cl were obtained from 149 study points because 47 pulse pressure values were missing (patients on concomitant left VAD). $p=0.058$ between ROC AUC of PP versus $\mathrm{EtCO}_{2}$ (Delong test)

prevent the risks associated with low NCO during VAECLS.

In the early phase of cardiovascular assistance in the case of severe CS, VA-ECLS is devoted to the restoration of blood flow to organs, a vital issue in avoiding multiple organ failure and death [22]. Therefore, low residual transpulmonary blood flow or NCO is common during the initial hours after VA-ECLS implantation [23]. In our series, owing to the fact that patients were included with $\mathrm{PP}<20 \mathrm{mmHg}$, a high incidence of Th-NCO was expected and $13(50 \%)$ patients did indeed have Th$\mathrm{NCO}$ at the first measurement. However, most Th-NCO episodes $(n=38,75 \%)$ occurred afterwards, despite global NCO improvement over time.

Not surprisingly, Th- $\mathrm{NCO}$ was associated with higher VA-ECLS flow, lower blood and pulmonary artery pressures, stable heart rate, and higher inotropic and vasopressor support (Table 2), a hemodynamic profile that underlines a high dependence on VA-ECLS. However, we also observed lower right atrial pressure and lower PAWP when NCO was $<1 \mathrm{~L} /$ min compared to $\mathrm{NCO} \geq 1$ $\mathrm{L} / \mathrm{min}$, suggesting that hypovolemia may have worsened the NCO. High VA-ECLS outflows are at greater risk of pulmonary circulation exclusion and left ventricle distension, and thus, related complications may occur. The study was not designed to explore these complications, but several publications have already reported risk of blood stasis, stroke incidence, or intra-cardiac or aortic root thrombosis [5, 6, 24, 25]. In our series, 4 (15\%) patients needed LV venting with Impella to avoid major complications, an incidence in agreement with previous studies [12, 13]. Poor prognosis of Th-NCO increases with its duration or episode repetition [7, 23]. Therefore, the monitoring of $\mathrm{NCO}$ is strongly recommended to avoid a prolonged cumulative time of Th-NCO [8].

In this respect, ELSO guidelines recommend the use of a PAC to maintain mean PAP $>30 \mathrm{mmHg}$, echocardiography to avoid non-opening of the aortic valve, and continuous arterial monitoring to track the non-pulsatile arterial line [8]. PAC is mandatory for measuring PAP, but it is an invasive monitoring method with a limited duration of utilization due to septic risk [26]. High PAP may also reflect left ventricular overload, through an elevation of PAWP, a major concern during VA-ECLS. Moreover, in our series, even when NCO exceeded $1 \mathrm{~L} /$ min, mean PAP was lower than $30 \mathrm{mmHg}$, which indeed seems like a rather difficult objective to achieve when patients are very VA-ECLS dependent. Incidentally, PAC with continuous thermodilution measurement of cardiac output cannot measure flows $<1 \mathrm{~L} / \mathrm{min}$ and becomes less reliable when cardiac output falls below $2 \mathrm{~L} / \mathrm{min}$, which makes PAC less useful in the condition of high level of ECLS assistance [15, 16]. The PAC limitation on cardiac output measurement in low flow states could be overcome with adaptation of the thermodilution technique, mainly with resetting catheter constant at various flow ranges [27]. Although attractive, the technique is currently not available in clinical practice.

A continuous monitoring of the arterial pressure line can evidence loss of pulsatility, and echocardiography may then confirm absence or rare openings of the aortic valve. The loss of pulsatility is associated with blood stasis and a high incidence of stroke (41\%) [6]. However, analysis of PP may go beyond the qualitative evaluation of the presence or absence of pulsatility. In physiology, PP is linearly related to the stroke volume and inversely related to arterial compliance [28]. In the nonphysiological condition of the VA-ECLS, PP was still strongly related to stroke volume, especially for lower stroke volume values. The NCO relationship with pulse pressure followed that of stroke volume, in agreement with a heart rate that remained constant. The weaker relationship with upper values might be explained by a reduction of VA-ECLS backflow pressure. VA-ECLS outflow was reduced proportionally to the improvement of NCO, therefore decreasing LV afterload, which is equivalent to an increase in arterial compliance [28]. Anyway, the good relation between low NCO levels and PP was exemplified by the ROC curve analysis, with excellent accuracy for predicting Th-NCO. However, PP monitoring may be limited by any venting technique 
involving the left ventricle, by aortic valve leaks, or by the presence of an intra-aortic balloon.

Conversely, $\mathrm{EtCO}_{2}$ appears as a very pertinent parameter, even when PP is not reliable. $\mathrm{EtCO}_{2}$ monitoring is a routine and non-invasive measure in ventilated patients. Recent studies have found a correlation between $\mathrm{NCO}$ and $\mathrm{EtCO}_{2}$ in patients requiring $\mathrm{LV}$ venting during VA-ECLS $[19,29]$. In the present study, we demonstrate that $\mathrm{EtCO}_{2}$ correlated strongly with $\mathrm{NCO}$ when $<2 \mathrm{~L} /$ min, and even that $\mathrm{EtCO}_{2}$ tended to have a better ability than PP to predict Th-NCO. This result corroborates Bachman and coworkers' study, which showed in an experimental model of VA-ECLS that the variation of $\mathrm{CO}_{2}$ elimination from the lungs correlated strongly with the variation of pulmonary blood flow [30]. Moreover, in our study, $\mathrm{PaCO}_{2}$ was measured as a control of effective $\mathrm{CO}_{2}$ removal by both lungs and ECLS. Owing to the facts that $\mathrm{PaCO}_{2}$ was in normal range and that sweep gas-to-blood flow ratio at ECLS as well as ventilator settings were unchanged, the $\mathrm{EtCO}_{2}$ changes followed the $\mathrm{NCO}$ quite well at low NCO levels. Indeed, in physiological conditions, when $\mathrm{CO}_{2}$ production is stable, the venous return allows $\mathrm{CO}_{2}$ transport to the lung where $\mathrm{CO}_{2}$ is removed from the blood through the regulation of pulmonary gas exchanges. $\mathrm{EtCO}_{2}$ is closely related to $\mathrm{PaCO}_{2}$, and the $\mathrm{PaCO}_{2}-\mathrm{EtCO}_{2}$ gradient is low (3-5 $\mathrm{mmHg}$ ) [31]. An $\mathrm{EtCO}_{2}$ decrease, with parallel increase of $\mathrm{PaCO}_{2}-\mathrm{EtCO}_{2}$ gradient, while $\mathrm{CO}_{2}$ production or gas exchanges are unchanged, reflects quite directly a decrease in venous return and pulmonary artery flow, generating alveolar dead space $[17,18,31,32]$. In the condition of VA-ECLS, a large amount of venous return is diverted to the membrane oxygenator by the ECLS circuit, but NCO keeps a fraction of the venous return for flow into the pulmonary artery towards the alveolar capillaries. Therefore, $\mathrm{CO}_{2}$ removal depends on ventilator and ECLS settings, but even with very low volume ventilation, $\mathrm{EtCO}_{2}$ variation parallels the changes in alveolar dead space related to low pulmonary artery blood flow. In our series, minute ventilation was low (median $3.6 \mathrm{~L} / \mathrm{min}$, which is roughly half the physiological value), but median $\mathrm{PaCO}_{2}$ $\mathrm{EtCO}_{2}$ gradient was $30 \mathrm{mmHg}$, i.e., 6-fold the normal range, when $\mathrm{NCO}$ was $<1 \mathrm{~L} / \mathrm{min}$. The $\mathrm{EtCO}_{2}$ kept going up when $\mathrm{NCO}$ increased above $1 \mathrm{~L} / \mathrm{min}$ but the relation between $\mathrm{EtCO}_{2}$ and $\mathrm{NCO}$ curved down significantly when $\mathrm{NCO}$ exceeded $2 \mathrm{~L} / \mathrm{min}$ (Fig. 2c), demonstrating that $\mathrm{EtCO}_{2}$ became independent on the NCO level when pulmonary vascular recruitment was completed. The limitation of $\mathrm{EtCO}_{2}$ monitoring is related to the access to exhaled $\mathrm{CO}_{2}$ that, in order to be trustable, needs the patient to be intubated.

Taken together, the two parameters offer a real-time, complementary monitoring method and could guide medical interventions (fluid loading, inotrope, cardiac pacing, VA-ECLS outflow titration, or left ventricle venting) for NCO optimization in situations of threatening NCO.

Our study has several limitations. It is a single-center nature study with a small number of patients and a strict control of lung and ECLS ventilations, and thus $\mathrm{PaCO}_{2}$. The ventilator and ECLS settings were fixed according to guidelines, which are routinely used in most ECLS centers. A quarter of the measures were made with concomitant left VAD support that induced missing data for PP. However, the association of transient or durable VAD with VA-ECLS is frequent and source of low NCO events. NCO monitoring is crucial in these patients and PP is not reliable. Based on previous observations [19], we thought that VAD do not impede interpretation of $\mathrm{EtCO} 2 / \mathrm{NCO}$ relationship, which is why we chose to include patients with VAD. PAC monitoring was considered as the gold standard for cardiac output measurement but its accuracy in cases of low cardiac output and in the setting of VAECLS is disputed [27]. Although echocardiography was used for $\mathrm{NCO}<1 \mathrm{~L} / \mathrm{min}$ (failure of $\mathrm{PAC}$ assessment), cross measurements for comparison of the 2 techniques above $1 \mathrm{~L} / \mathrm{min}$ would have been interesting. Finally, cardiac thrombosis and stroke incidences were not documented in this study, but recommended actions to prevent them (including LV venting) were applied when appropriate. The study was based on a physiological approach, and the small number of patients included would not allow any significant clinical assumption.

\section{Conclusions}

The study shows that PP and $\mathrm{EtCO}_{2}$ are interesting parameters to monitor residual native cardiac output during VA-ECLS, specifically for detecting threatening NCO. Thresholds of $\mathrm{PP}<15 \mathrm{mmHg}$ and $\mathrm{EtCO}_{2}<14 \mathrm{mmHg}$ predicted $\mathrm{NCO}<1 \mathrm{~L} / \mathrm{min}$ with good accuracy. Further studies are needed to show if their utilization may help to implement therapeutic strategies in order to prevent thromboembolic and respiratory complications associated with VA-ECLS, and to improve patients' prognosis.

\section{Abbreviations \\ AUC: Area under the curve; CS: Cardiogenic shock; $\mathrm{EtCO}_{2}$ : End-tidal carbon dioxide; ICU: Intensive care unit; LV: Left ventricular; NCO: Native cardiac output; PAC: Pulmonary artery catheter; PAP: Pulmonary artery pressure; PAWP: Pulmonary arterial wedge pressure; PP: Pulse pressure; ROC: Receiver operating characteristics; SEC: Spontaneous echo contrast; Th- NCO: Threatening NCO; VA-ECLS: Veno-arterial extracorporeal life support; VAD: Ventricular assist device}

\section{Acknowledgements}

Not applicable.

\section{Authors' contributions}

MM was involved in the conception of the study, in the interpretation of the data, and in drafting the manuscript. EJ was involved in the study design and in revising the manuscript. ZN, SM, and SP contributed to the data 
acquisition and drafting of the manuscript. MF and MN were involved in the statistical design and analysis of the study and in revising the manuscript. GT was involved in all surgical aspects of the study design and in revising the manuscript. CP and GP were involved in the interpretation of data and in revising the manuscript. All authors approved the final manuscript to be published and are accountable for all aspects of the work.

\section{Funding}

Montpellier University Hospital

\section{Availability of data and materials}

The datasets used and/or analyzed during the current study are available from the corresponding author on reasonable request.

\section{Ethics approval and consent to participate}

Our institutional review board had approved the study design (CPP Sud Mediterranée 1; ID RCB: 2015-A02006-43). Informed consent was obtained from all patients or their surrogates. The trial was registered on Clinical Trials on July 12, 2016 (NCT03323268)

\section{Consent for publication}

Not applicable.

\section{Competing interests}

The authors declare that they have no competing interests.

\section{Author details}

'Department of Anesthesiology and Critical Care Medicine, Arnaud de Villeneuve Hospital, CHU Montpellier, Univ Montpellier, Montpellier, France. 'Epidemiology and Clinical Research Department, CHU Montpellier, Univ Montpellier, Montpellier, France. ${ }^{3}$ Department of Cardiac Surgery, CHU Montpellier, Univ Montpellier, Montpellier, France. ${ }^{4}$ Univ Montpellier, CNRS, INSERM, Institut de Génomique Fonctionnelle, Montpellier, France. ${ }^{5}$ Univ Montpellier, CNRS, INSERM, PhyMedExp, Montpellier, France.

Received: 19 June 2020 Accepted: 10 September 2020

Published online: 22 September 2020

\section{References}

1. Stretch $\mathrm{R}$, Sauer CM, Yuh DD, et al. National trends in the utilization of short-term mechanical circulatory support: incidence, outcomes, and cost analysis. J Am Coll Cardiol. 2014;64:1407-15.

2. Combes A, Leprince P, Luyt C-E, et al. Outcomes and long-term quality-oflife of patients supported by extracorporeal membrane oxygenation for refractory cardiogenic shock. Crit Care Med. 2008;36:1404-11.

3. Chen Y-S, Lin J-W, Yu H-Y, et al. Cardiopulmonary resuscitation with assisted extracorporeal life-support versus conventional cardiopulmonary resuscitation in adults with in-hospital cardiac arrest: an observational study and propensity analysis. Lancet Lond Engl. 2008;372:554-61.

4. Vardi $\mathrm{A}$, Jessen ME, Chao RY, et al. Effect of extracorporeal membrane oxygenation flow on pulmonary capillary blood flow. Crit Care Med. 1995;23:726-32.

5. Williams B, Bernstein W. Review of venoarterial extracorporeal membrane oxygenation and development of intracardiac thrombosis in adult cardiothoracic patients. J Extra Corpor Technol. 2016:48:162-7.

6. Unai $S$, Nguyen $M-L$, Tanaka $D$, et al. Clinical significance of spontaneous echo contrast on extracorporeal membrane oxygenation. Ann Thorac Surg 2017;103:773-8.

7. Koul B, Wollmer $\mathrm{P}$, Willen $\mathrm{H}$, et al. Venoarterial extracorporeal membrane oxygenation--how safe is it? Evaluation with a new experimental model. Thorac Cardiovasc Surg. 1992;104:579-84.

8. Extracorporeal Life Support Organization: ELSO Adult Cardiac Failure Supplement to the ELSO General Guidelines v1.3. Ann Arbor; 2013. http:// elso.org/.

9. Truby L, Hart S, Takeda K, et al. Management and outcome of left ventricular distention during venoarterial extracorporeal membrane oxygenation support. J Heart Lung Transplant. 2015:34:S83-4.

10. Cevasco M, Takayama $H$, Ando M, et al. Left ventricular distension and venting strategies for patients on venoarterial extracorporeal membrane oxygenation. J Thorac Dis. 2019;11:1676-83.

11. Schrage B, Becher M, Schwarzl M, et al. Percutaneous unloading of the left ventricle during extracorporeal membrane oxygenation in cardiogenic shock - ongoing experience from a high-volume centre. J Heart Lung Transplant. 2018:37:S28.

12. Gaudard P, Mourad M, Eliet J, et al. Management and outcome of patients supported with Impella 5.0 for refractory cardiogenic shock. Crit Care Lond Engl. 2015;19:363.

13. Mourad M, Gaudard P, De La Arena P, et al. Circulatory support with extracorporeal membrane oxygenation and/or Impella for cardiogenic shock during myocardial infarction. ASAIO J. 2018;64:708-14.

14. Russo JJ, Aleksova N, lan P, et al. Left ventricular unloading during extracorporeal membrane oxygenation in patients with cardiogenic shock. Am Coll Cardiol. 2019:73:654-62.

15. Norris SL, King EG, Grace M, et al. Thermodilution cardiac output--an in vitro model of low flow states. Crit Care Med. 1986:14:57-9.

16. Reuter DA, Huang C, Edrich T, et al. Cardiac output monitoring using indicator-dilution techniques: basics, limits, and perspectives. Anesth Analg. 2010;110:799-811.

17. Shibutani K, Muraoka M, Shirasaki S, et al. Do changes in end-tidal PCO2 quantitatively reflect changes in cardiac output? Anesth Analg. 1994;79:829-83.

18. Maslow A, Stearns G, Bert A, et al. Monitoring end-tidal carbon dioxide during weaning from cardiopulmonary bypass in patients without significant lung disease. Anesth Analg. 2001;92:306-13.

19. Eliet J, Gaudard P, Zeroual N, et al. Effect of Impella during veno-arterial extracorporeal membrane oxygenation on pulmonary artery flow as assessed by end-tidal carbon dioxide. ASAIO J. 2018:64:502-7.

20. Schmidt M, Pellegrino V, Combes A, et al. Mechanical ventilation during extracorporeal membrane oxygenation. Crit Care Lond Engl. 2014;18:203.

21. Peter Bruce, Andrew Bruce. Practical statistics for data scientists. Sebastopol: O'Reilly Media; 2017.

22. Rao P, Khalpey Z, Smith R, Burkhoo D, Kociol RD. Venoarterial extracorporeal membrane oxygenation for cardiogenic shock and cardiac arrest. Circ Heart Fail. 2018;11:e004905.

23. Park B-W, Seo D-C, Moon I-K, et al. Pulse pressure as a prognostic marker in patients receiving extracorporeal life support. Resuscitation. 2013:84:1404-8.

24. Weber C, Deppe A-C, Sabashnikov A, et al. Left ventricular thrombus formation in patients undergoing femoral veno-arterial extracorporeal membrane oxygenation. Perfusion. 2018;33:283-28.

25. Madershahian N, Weber C, Scherner M, et al. Thrombosis of the aortic root and ascending aorta during extracorporeal membrane oxygenation. Intensive Care Med. 2014:40:432-43.

26. Haller M, Zöllner C, Briegel J, et al. Evaluation of a new continuous thermodilution cardiac output monitor in critically ill patients: a prospective criterion standard study. Crit Care Med. 1995:23:860-6.

27. Bachmann KF, Zwicker L, Nettelbeck K, Casoni D, Heinisch PP, Jenni H, Haenggi M, Berger D. Assessment of right heart function during extracorporeal therapy by modified thermodilution in a porcine model Anesthesiology 2020. No Pagination Specified. https://doi.org/10.1097/ALN. 0000000000003443.

28. Vennin S, Li Y, Willemet $M$, et al. Identifying hemodynamic determinants of pulse pressure. A combine numerical and physiological approach. Hypertension. 2017:70:1176-82

29. Lim HS. The effect of Impella CP on cardiopulmonary physiology during venoarterial extracorporeal membrane oxygenation support. Artif Organs. 2017:41:1109-12.

30. Bachmann KF, Haenggi M, Jakob S, Takala J, Gattinoni L, Berger D. Gas exchange calculation may estimate changes in pulmonary blood flow during veno-arterial extracorporeal membrane oxygenation in a porcine model. Am J Physiol Lung Cell Mol Physiol. 2020:318:L1211-21.

31. Downs JB. PaCO2, EtCO2 and gradient. In: CAPNOGRAPHY 2nd edition, Gravenstein JS, Jaffe MB, Gravenstein N, Paulus DA, editors. Cambridge: Cambridge University Press; 2011. p. 225-30.

32. Isserles SA, Breen PH. Can changes in end-tidal PCO2 measure changes in cardiac output? Anesth Analg. 1991;73:808-14.

\section{Publisher's Note}

Springer Nature remains neutral with regard to jurisdictional claims in published maps and institutional affiliations. 